\title{
Risk Factors for Developing Diabetic Peripheral Neuropathy: a Meta-analysis
}

\author{
Tirzah M. Fakkel ${ }^{1,2}$ (D) Nuray Çakici ${ }^{1} \cdot$ J. Henk Coert ${ }^{2} \cdot$ Arianne P. Verhagen $^{3} \cdot$ Wichor M. Bramer $^{4} \cdot$ Johan W. van Neck $^{1}$
}

Accepted: 20 August 2020 / Published online: 29 August 2020

(C) The Author(s) 2020

\begin{abstract}
To identify risk factors for the development of diabetic peripheral neuropathy, systematic searches of PubMed, Embase, Web-ofScience, Cochrane and Google scholar databases were performed to conduct a meta-analysis of prospective studies that quantified major risk factors for diabetic peripheral neuropathy. Two authors independently extracted data for a random-effects metaanalysis. The standardized mean difference (SMD) and 95\% CI for continuous data, and an odds ratio (OR) and 95\% CI for dichotomous data were calculated. Of 7473 studies retrieved, 16 qualified studies were included. Contributing risk factors for developing diabetic peripheral neuropathy were age $(\mathrm{SMD}=0.36 ; \mathrm{CI}, 0.19$ to $0.54 ; P<0.01)$, body mass index ( $\mathrm{SMD}=0.31 ; \mathrm{CI}$, 0.20 to $0.42 ; P<0.01$ ), diabetes duration ( $\mathrm{SMD}=0.47 ; \mathrm{CI}, 0.30$ to $0.65 ; P<0.01$ ), estimated glomerular filtration rate $(\mathrm{SMD}=-$ $0.45 ; \mathrm{CI},-0.63$ to $-0.27 ; P<0.01$ ), fibrinogen (SMD $=0.10 ; \mathrm{CI}, 0.01$ to $0.19 ; P=0.03$ ), haemoglobin A1c (SMD = 0.24; $\mathrm{CI}$, 0.16 to $0.32 ; P<0.01$ ), high-density lipoproteins ( $\mathrm{SMD}=-0.14 ; \mathrm{CI},-0.21$ to $-0.06 ; P<0.01)$ systolic blood pressure $(\mathrm{SMD}=$ $0.31 ; \mathrm{CI}, 0.10$ to $0.52 ; P<0.01$ ), waist circumference (SMD $=0.39 ; \mathrm{CI}, 0.14$ to $0.64 ; P<0.01$ ), weight (SMD $=0.34 ; \mathrm{CI}, 0.24$ to $0.43 ; P<0.01)$, cardiovascular disease $(\mathrm{OR}=2.22 ; \mathrm{CI}, 1.75$ to $2.81 ; P<0.01)$, foot ulcer history $(\mathrm{OR}=1.90 ; \mathrm{CI}, 1.09$ to 3.33 ; $P=0.02$ ), hypertension ( $\mathrm{OR}=1.90 ; \mathrm{CI}, 1.24$ to $2.89 ; P<0.01$ ), macroalbuminuria ( $\mathrm{OR}=2.96 ; \mathrm{CI}, 2.02$ to $4.35 ; P<0.01)$, microor macroalbuminuria $(\mathrm{OR}=1.73 ; \mathrm{CI}, 1.43$ to $2.08 ; P<0.01)$, proliferative retinopathy $(\mathrm{OR}=2.48 ; \mathrm{CI}, 1.80$ to $3.41 ; P<0.01)$ and retinopathy $(\mathrm{OR}=2.19 ; \mathrm{CI}, 1.84$ to $2.62 ; P<0.01)$. Our findings show 17 risk factors that significantly contribute to the development of diabetic peripheral neuropathy.
\end{abstract}

Keywords Diabetic neuropathy $\cdot$ Diabetic foot $\cdot$ Risk factors $\cdot$ Meta-analysis

Tirzah M. Fakkel and Nuray Çakici contributed equally to this work.

This article is part of the Topical Collection on Medicine

Electronic supplementary material The online version of this article (https://doi.org/10.1007/s42399-020-00480-0) contains supplementary material, which is available to authorized users.

Tirzah M. Fakkel

T.M.Fakkel@umcutrecht.nl

1 Department of Plastic and Reconstructive Surgery, Erasmus University Medical Center, Rotterdam, The Netherlands

2 Department of Plastic-, Reconstructive- and Hand Surgery, Utrecht University Medical Center, Utrecht, The Netherlands

3 Department of Physiotherapy, University of Technology Sydney, Sydney, Australia

4 Department of Biostatistics, Erasmus University Medical Center, Rotterdam, The Netherlands

\section{Introduction}

Diabetic peripheral neuropathy (DPN) is a frequently occurring chronic complication in people with diabetes [1-5], up to $50 \%$ of whom are affected with DPN [6]. DPN is associated with increased mortality [4, 7-9], lower quality of life [4, 7, $10,11]$ and substantial morbidity [7-10] such as foot ulcerations and amputations $[3,8,10-13]$, which also results in a large economic burden [7, 9-11]. DPN has an insidious onset in people with diabetes and is irreversible [3]. Since people with diabetes are usually asymptomatic in the early stages of DPN, prevention methods and foot care training for preventing DPN complications can only be put into practise if individuals are identified in the early stages of the disease $[12,14]$.

The exact pathogenesis of DPN is still unclear $[1,4]$. Previous studies have identified poor glycaemic control as a major risk factor for the development of DPN $[7,10,11,15$, 16]. Proper glycaemic control is the only known treatment option to prevent or ease DPN [9]. Hypertension, smoking 
and dyslipidaemia also have been associated with the development of DPN [17, 18]. Further identification of modifiable risk factors will provide improved insight into the pathogenesis of DPN and may lead to new strategies for risk reduction $[7,9,16]$, thereby reducing morbidity [2]. As a complete overview of meta-analytic evidence of risk factors for developing DPN is lacking, the aim of this meta-analysis of prospective studies is to identify significant risk factors that contribute to the development of DPN.

\section{Material and Methods}

\section{Data Sources and Searches}

The electronic search for relevant literature was based on PubMed, Embase, Web-of-Science, Cochrane and Google scholar databases up to October 5, 2018. The search strategy focused on diabetes type 1 , type 2 and diabetic polyneuropathy. A total of 12,313 potentially relevant citations were screened by the lead authors (TF and NÇ). The following keywords were used: peripheral neuropathy, diabetic neuropathy, risk factor or risk assessment. The complete search strategy is presented in Supplemental Table S1. No language restrictions were applied.

\section{Study Selection}

Two reviewers (TF and NÇ) independently selected potentially relevant prospective trials by titles and abstracts. The consensus was achieved by a third reviewer $(\mathrm{JWvN})$ if the two initial reviewers disagreed. Articles were included if incident DPN was the outcome of the investigated risk factors. Exclusion criteria were as follows: (1) study design other than a prospective study, (2) incomplete data, (3) no unadjusted measurements available for risk factors presented as mean and standard deviation or in frequency tables (4) investigating risk factors for the prevalent DPN population only (5) peripheral neuropathy due to causes other than diabetes (6) studies focusing solely on minors. The flowchart of the study selection can be found in Fig. 1.

\section{Quality Assessment}

Two authors (TF and NÇ) independently evaluated the quality of the included articles which met the selection criteria. These articles were graded by a Dutch quality assessment form for evidence-based practice of the Dutch Cochrane Centre [19]. This list consists of thirteen items, nine of which were used to assess the quality of the articles. Item one relates to the eligibility of the study population and the prognostic comparability of study groups. The second item describes the inclusion and exclusion criteria of the study population to check for selection bias. The third item describes the exposure and its rating method. The fourth item describes the outcome and its rating method. The fifth item describes the blinding procedure. The sixth item focuses on the length of follow-up. The seventh item describes selective loss-to-follow-up. Item number eight relates to the eligibility of the confounders and prognostic factors as well as the study design and analysis. The last item we used to calculate the risk of bias of each article, evaluating the validity and enforceability of the results. We refrained from using the items $10-13$ that describe the summary and conclusion of the article.

All items have the answer options 'yes', 'no' or 'do not know'. One point is granted when 'yes' is chosen. We used a threshold of 55\% (a minimum of 5 out of 9 points) of the score to define the cutoff point between the high and low risk of bias. Only low-risk studies were included. The total score for each article is provided in Supplemental Table S2.

\section{Data Extraction}

Data on the outcome measures of the articles were extracted independently by two authors (TF and NÇ) using the PRISMA guidelines [20]. Disagreements were resolved by discussion with a third reviewer $(\mathrm{JWvN})$. The meta-analysis is registered in PROSPERO, ID: CRD42018024946.

\section{Primary Outcomes}

Baseline characteristics were compared with the characteristics at the end of the follow-up period. People with diabetes, who developed DPN during the follow-up period, were compared to people with diabetes free of DPN. We focused on primary outcomes measuring potential risk factors for DPN. Binary and continuous data of the risk factors were used to calculate OR and standardized mean difference (SMD).

\section{Data Analysis}

For continuous data, we calculated SMD, represented as Hedges' $g$, and 95\% CI [21]. Study mean differences are first standardized and subsequent weighting is applied. Therefore, effect sizes can be directly compared across different measurement scales. A SMD of 0.2 represents a small effect, 0.5 a medium effect and 0.8 and over represents a large effect [22]. Dichotomous data were analysed by calculating the OR and 95\% CI from frequency tables. We summarized the data using the inverse variance method. We deemed a 2 -tailed $P<0.05$ as significant. We used the method of DerSimonian and Laird (1986) for calculating the random-effects pooled effect size and $95 \%$ confidence interval to provide a lower type I error and wider confidence intervals [23]. We assessed heterogeneity across studies using the Cochran Q statistic [24]. We assessed inconsistency across studies using the I2 statistic, 
Fig. 1 Flowchart of study selection
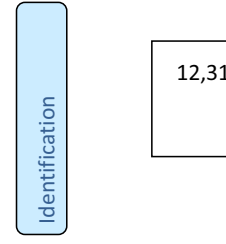

12,313 Records identified through database searching
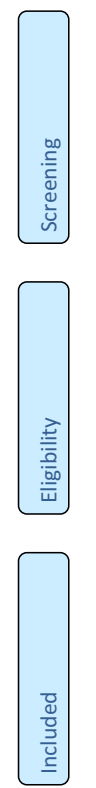

with assigning adjectives of low, moderate and high heterogeneity to $I^{2}$ values of $0-<25 \%, 25-75 \%$ and $>75 \%$ [25]. Publication bias was assessed using the Egger test of the intercept [26], if 10 or more studies were analysed for the same protein marker with funnel plots [27]. All analyses were performed in R software 3.4.0 [28].

\section{Definition of DPN}

We included only prospective cohort studies in our metaanalysis with a study population of participants with diabetes who were strictly free from DPN in the feet at the onset of the study. Notably, each included prospective cohort study used a different diagnostic method to identify new cases of DPN. In our included studies, the definition of DPN was defined by either signs and symptoms of DPN, physical examination, nerve conduction studies or a combination of these diagnostic methods. However, most studies used multiple methods to identify DPN. Diagnostic methods for DPN include nerve conduction studies vibration perception threshold, sudoscan, dynamometry, pinprick test, biothesiometer measurements, monofilament sensation, tendon reflexes and neuropathy symptom score and Michigan Neuropathy Screening Instrument Questionnaire. Supplemental Table S3 gives an overview of the definitions of diabetic neuropathy used in these studies.

\section{Results}

\section{Retrieved Studies}

A total of 7473 studies were retrieved, of which 16 studies met our inclusion criteria. The flowchart of the study selection procedure can be found in Fig. 1.

\section{Study Characteristics}

Table 1 gives an overview of the study-specific baseline characteristics of the included studies. There was a wide range in sample size (50 to 37,375 participants). The mean age ranged from 30.2 to 72.5 years. The type of diabetes differed among the studies. Seven studies included participants with type 1 diabetes, five studies included participants with only type 2 diabetes and four studies included participants with both type 1 or type 2 diabetes. The included studies were spread out over the continents Europe, Asia, North America, Australia and Asia. The follow-up time ranged from 3.3 to 13 years.

\section{Methodology}

The Dutch quality assessment form, for evidence-based practice of the Dutch Cochrane Centre, was used to evaluate the degree of bias of each study. We used a threshold of $50 \%$ of the score ( 5 or more out of 9 ) to define the borderline between 


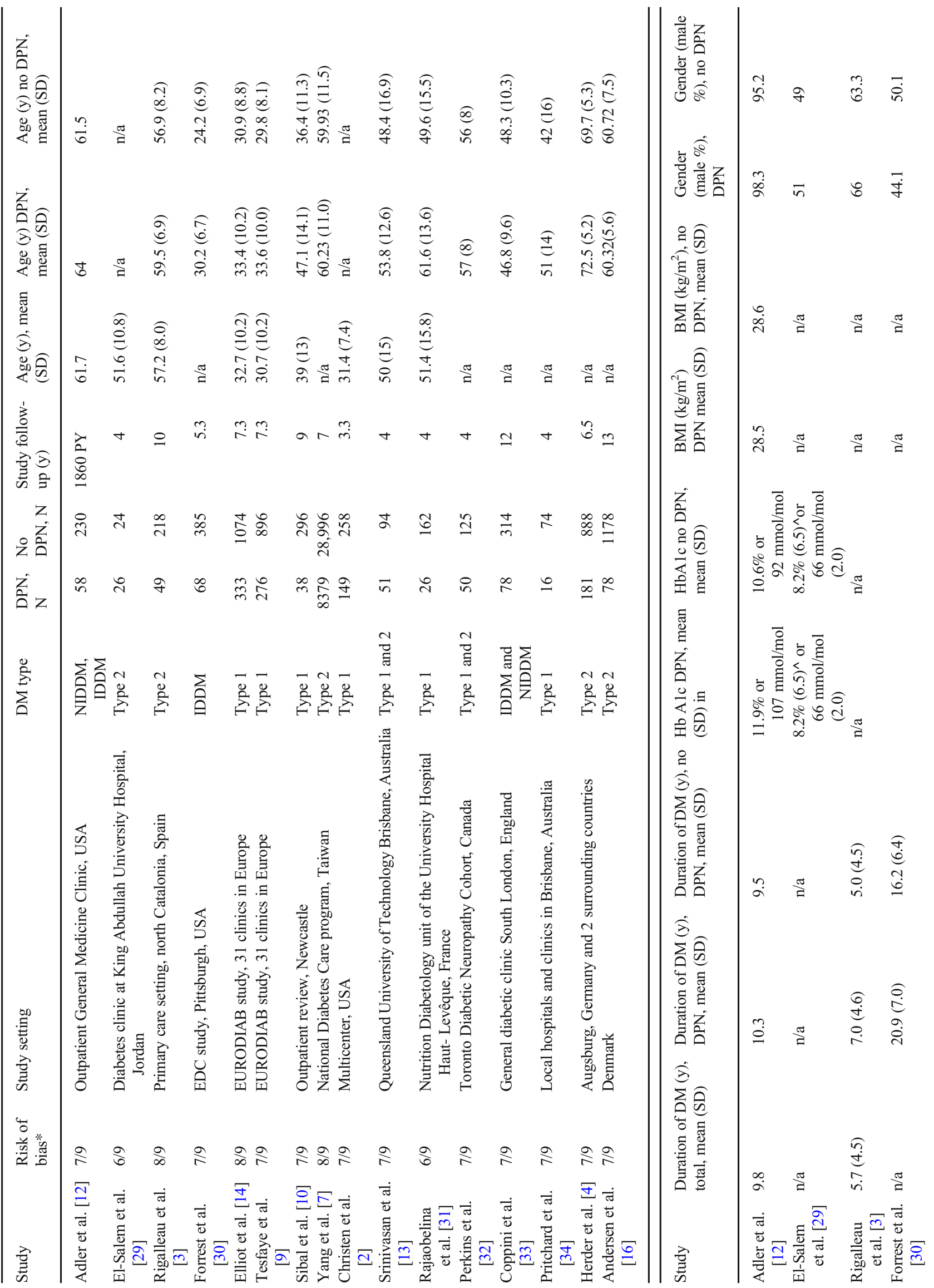




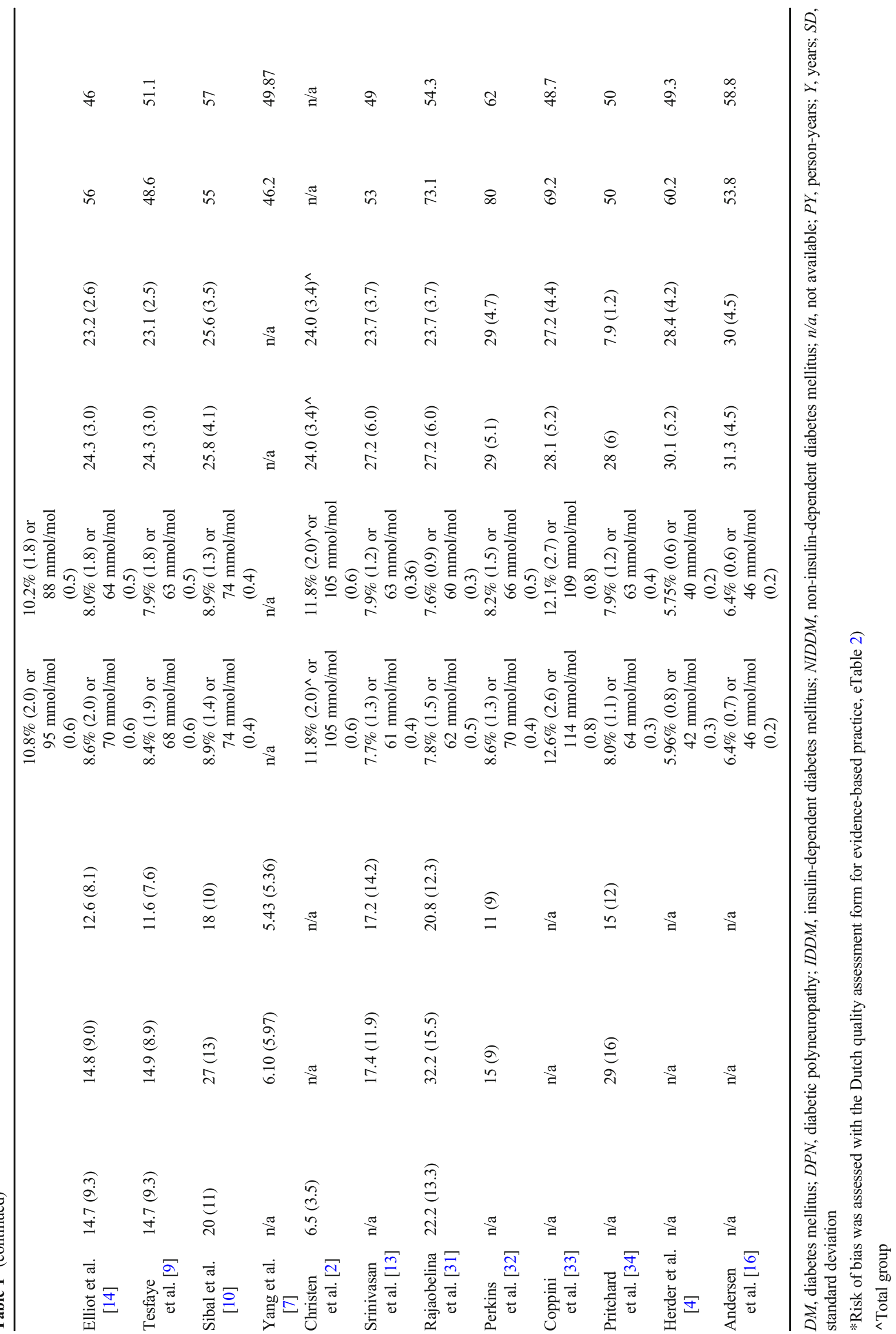


the high and low risk of bias. There was a small range of quality scores for the included studies. The lowest score was 6 out of 9 points and was only seen in two included studies $[29,31]$. Most articles scored 7 out of 9 points for the quality assessment $[2,4,9,10,12,13,16,30,32-34]$. Three articles scored 8 out of 9 points $[3,7,14]$. All included studies scored low in the risk of bias. The details of the quality assessment can be found in Supplemental Table S2.

\section{Risk Factors for Incident Diabetic Neuropathy}

Of the 16 included articles, comprised of 45,131 participants, 38 different risk factors were analysed for the development of new-onset DPN. All risk factors, including its degree of association with DPN, are summarized in Table 2.

An overview of the risk factors for DPN is presented in Figs. 2 and 3. Supplemental Fig. S1 and 2 present the forest plots of the risk factors including funnel plots. Supplemental Table S4 and 5 give an overview of the binary and continuous data used for meta-analysis.

\section{Significant Risk Factors}

Risk factors which contributed significantly to developing DPN were age, BMI, duration of diabetes, estimated glomerular filtration rate (eGFR), fibrinogen, haemoglobin A1c (HbA1c), high-density lipoproteins (HDL), systolic blood pressure, waist circumference, weight, cardiovascular disease, foot ulcer history, hypertension, macroalbuminuria, micro- or macroalbuminuria, proliferative retinopathy and retinopathy.

\section{Age}

Age as a risk factor for DPN was investigated in 13 studies comprising of 44,323 participants with diabetes, of which 9623 developed DPN over time. Higher age was a significant risk factor for developing DPN (SMD, 0.36; 95\% CI, 0.19 to $0.54 ; P<0.01)$.

\section{BMI}

The risk factor BMI was measured in 10 studies comprising of 6228 participants with diabetes of which 1127 developed DPN during follow-up. Increased BMI was significantly associated with the development of DPN in participants with diabetes (SMD, 0.31; CI, 0.20 to $0.42 ; P<0.01$ ).

\section{Duration of Diabetes}

Duration of diabetes as a risk factor was analysed using data of 10 studies comprising of 32,369 participants with diabetes of which 9286 developed incident DPN. A longer duration of diabetes was found to be a significant risk factor for developing DPN (SMD, 0.47; 95\% CI, 0.30 to $0.65 ; P<0.01$ ).

\section{eGFR}

The risk factor eGFR was analysed using data of 4 studies comprising of 1681 participants with diabetes in total, of which incident DPN occurred in 261 participants. A low eGFR showed to be a significant risk factor for developing DPN (SMD, $-0.45 ; 95 \%$ CI, -0.63 to $-0.27 ; P<0.01$ ).

\section{Fibrinogen}

Fibrinogen as a risk factor for DPN was investigated in 3 studies comprising of 3032 participants with diabetes who developed DPN over time. Six hundred seventy-seven participants eventually developed incident DPN. High fibrinogen levels showed to be a significant risk factor for developing DPN (SMD, 0.10; 95\% CI, 0.01 to $0.19 ; P=0.03$ ).

\section{HbA1c}

$\mathrm{HbAl} \mathrm{c}$ was measured in 9 studies comprising of 5129 participants with diabetes of which 811 eventually developed DPN. A high $\mathrm{HbAlc}$ was significantly associated with the development of DPN in participants with diabetes (SMD, 0.21; 95\% CI, 0.16 to $0.32 ; P<0.01)$.

HDL

The risk factor HDL was analysed using data of 7 studies comprising of 5781 participants in total, of which 990 developed incident DPN. A low HDL was found to be a significant risk factor for developing DPN (SMD, $-0.14 ; 95 \% \mathrm{CI},-0.21$ to $-0.06 ; P<0.01)$.

\section{Systolic Blood Pressure}

The risk factor systolic blood pressure was analysed using data of 6 studies comprising of 2453 participants with diabetes. Eventually, 301 participants developed incident DPN. A high systolic blood pressure was found to be a significant risk factor for developing DPN (SMD, $0.31 ; 95 \%$ CI, 0.10 to 0.52 ; $P<0.01)$.

\section{Waist Circumference}

We analysed 3 studies which investigated waist circumference as a risk factor for DPN. These studies were comprised of 2415 participants with diabetes in total, of which 275 developed DPN over time. Increased waist circumference contributes significantly to the development of DPN (SMD, 0.39; 95\% CI, 0.14 to $0.64 ; P<0.01$ ). 
Weight

Weight was measured in 5 studies comprised of 4100 participants with diabetes in total, of which 753 eventually developed DPN. Higher weight was significantly associated with the development of DPN in participants with diabetes (SMD, $0.34 ; 95 \% \mathrm{CI}, 0.24$ to $0.43 ; P<0.01)$.

\section{Cardiovascular Disease}

Cardiovascular disease as a risk factor for DPN was investigated in 6 studies comprised of 5505 participants with diabetes, of which 955 developed DPN over time. The presence of cardiovascular disease showed to be a significant risk factor for developing DPN (OR, 2.22; 95\% CI, 1.75 to 2.81; $P<0.01$ ).

\section{Foot Ulcer History}

Foot ulcer history as a risk factor was analysed using data of 2 studies comprised of 463 participants with diabetes in total. One hundred eight participants developed DPN during follow-up. A history of foot ulceration was found to be a significant risk factor for developing DPN (OR, 1.90; 95\% CI, 1.09 to $3.33 ; P=0.02$ ).

\section{Hypertension}

The risk factor of hypertension was investigated in 8 studies comprised of 42,405 participants with diabetes. During follow-up, 9450 participants developed DPN. Hypertension contributed significantly to the development of DPN (OR, 1.90; 95\% CI, 1.24 to $2.89 ; P<0.01)$.

\section{Macroalbuminuria}

The risk factor macroalbuminuria was analysed using data of 2 studies comprising of 2579 participants with diabetes, of which 609 developed DPN. Macroalbuminuria was found to be a significant risk factor for developing DPN (OR, 2.96; 95\% CI, 2.02 to $4.35 ; P<0.01)$.

\section{Micro- or Macroalbuminuria}

The risk factor of having either microalbuminuria or macroalbuminuria was measured in 4 studies comprised of 3366 participants with diabetes of which 715 developed DPN during follow-up. The presence of either microalbuminuria or macroalbuminuria was significantly associated with the development of DPN in participants with diabetes (OR, $1.73 ; 95 \% \mathrm{CI}, 1.43$ to $2.08 ; P<0.01)$.

\section{Proliferative Retinopathy}

Proliferative retinopathy as a risk factor for DPN was investigated in 3 studies comprised of 3032 participants with diabetes of which 677 developed DPN at follow-up. Proliferative retinopathy was found to be a significant risk factor for developing DPN (OR, 2.48; 95\% CI, 1.80 to $3.41 ; P<0.01$ ).

\section{Retinopathy}

Retinopathy as a risk factor for DPN was investigated in 3 studies comprised of 2971 participants with diabetes of which 687 developed DPN. Proliferative retinopathy was found to be a significant risk factor for developing DPN (OR, 2.19; 95\% CI, 1.84 to $2.62 ; P<0.01)$.

\section{Past Smoking}

Past smoking was analysed using data of 5 studies comprised of 5311 participants with diabetes, of which 1017 participants developed DPN at follow-up. Four studies showed that a history of smoking was a risk factor for developing DPN $[2,4,9$, 14]. Only one study showed controversial results [16]. Eventually, we observed a significant trend for past smoking as a risk factor for developing DPN (OR, 1.31; 95\% CI, 0.98 to $1.74 ; P=0.07$ ).

\section{Non-significant Risk Factors}

The analysed risk factors male sex, female sex, height, diastolic blood pressure, total cholesterol, insulin use, insulin dose, white race, alcohol use, excess alcohol use, current smoking, number of cigarettes per day, waist to hip ratio, albumin/creatinine ratio and LDL were not significantly associated to contribute as risk factors for developing DPN.

\section{Discussion}

In this meta-analysis, consisting of 16 prospective studies, we investigated risk factors significantly associated with the development of DPN. Age, BMI, duration of diabetes, eGFR, fibrinogen, $\mathrm{HbAlc}$, HDL, systolic blood pressure, waist circumference, weight, cardiovascular disease, foot ulcer history, hypertension, macroalbuminuria, micro- or macroalbuminuria, proliferative retinopathy and retinopathy are risk factors which contribute to the development of DPN. The participants in these studies were evaluated for DPN at baseline and were screened for new-onset DPN during their follow-up period.

To the best of our knowledge, a complete overview of meta-analytic evidence of risk factors for incident 
Table 2 Level of evidence for each risk factor

\begin{tabular}{|c|c|c|}
\hline Risk factor & Degree of association & References \\
\hline Age & ++ & {$[3,4,7,9,10,13,14,16,30-34,35]$} \\
\hline Body mass index & ++ & {$[4,9,10,13,14,16,30,33,34,35]$} \\
\hline Cardiovascular disease & + & {$[3,4,9,10,14,16]$} \\
\hline Duration of DM & + & {$[3,7,9,10,13,14,30-33,35]$} \\
\hline eGFR (low) & + & {$[4,9,14,32]$} \\
\hline Foot ulcer history & + & {$[12,33]$} \\
\hline $\mathrm{HbAlc}$ & ++ & {$[4,9,10,16,30-34,35]$} \\
\hline HDL (low) & + & {$[4,9,10,14,16,3235]$} \\
\hline Hypertension & + & {$[2,4,7,9,10,14,30,32]$} \\
\hline Macroalbuminuria & ++ & {$[9,14]$} \\
\hline Micro or macroalbuminuria & + & {$[9,10,14,32]$} \\
\hline Proliferative retinopathy & ++ & {$[9,14,32]$} \\
\hline Retinopathy & + & {$[9,14,34]$} \\
\hline Systolic blood pressure & ++ & {$[10,13,16,32,33,35]$} \\
\hline Waist circumference & ++ & {$[4,16,35]$} \\
\hline Weight & ++ & {$[9,14,16,33,35]$} \\
\hline Ace inhibitor use & + & {$[10,33]$} \\
\hline Fibrinogen & + & {$[9,14,32]$} \\
\hline LDL (high) & + & {$[4,9,10,14,16,32,35]$} \\
\hline Albumin creatinine ratio & - & {$[13,35]$} \\
\hline Alcohol use & - & {$[7,10,12,32]$} \\
\hline Current smoking & - & {$[2,4,7,10,12,16,30,32,34]$} \\
\hline Diastolic blood pressure & - & {$[1013,16,32,33,35]$} \\
\hline Excess Alcohol & - & {$[2,4,10,16]$} \\
\hline Female gender & - & {$[2-4,13,30,, 35]$} \\
\hline Height & - & {$[4,9,10,14,16,31,32,3334,35]$} \\
\hline Male gender & - & {$[2,4,7,9,10,12-14,16,30-35]$} \\
\hline Height & - & {$[4,9,10,14,16,30-34,35]$} \\
\hline Insulin use & - & {$[7,30,35]$} \\
\hline Insulin dose & - & {$[9,14]$} \\
\hline Past Smoker & - & {$[2,4,9,14,16]$} \\
\hline Smoking number of cigarettes/day & - & {$[13,35]$} \\
\hline Statin use & - & {$[10,16]$} \\
\hline Total cholesterol & - & {$[4,9,10,13,14,16,35]$} \\
\hline Triglycerides & - & {$[4,13,16,32,35]$} \\
\hline Waist to hip ratio & - & {$[9,14]$} \\
\hline White race & - & {$[12,35]$} \\
\hline
\end{tabular}

In respect to the continuous variables: $\mathrm{SMD}<0.2=+$ (small association); SMD $0.2-0.8=++$ (moderate association); SMD $>0.8=+++$ (strong association)

In respect to the binary variables: OR $1.0-2.0=-$ (no association); OR $1.2-1.5=+$ (weak association); OR $1.5-$ $3.0=++($ moderate association); OR 3.0-10.0 $=+++$ (strong association); OR $>10.0=++++$ (approaching infinity)

$D M$, diabetes mellitus; $H D L$, high-density lipoprotein; $L D L$, low-density lipoprotein
DPN has not yet been published. This overview of risk factors allows healthcare providers to concentrate on monitoring factors that are most likely associated with developing DPN and also on improving treatment strategies for persons with diabetes.
Cardiovascular risk factors, which also play a significant role in DPN, can be managed by risk reduction strategies and prevention methods.

Based on our findings, we want to advise people with diabetes not only to strive for normoglycaemia and normal 
Fig. 2 Risk factors for diabetic peripheral neuropathy (binary variables)

Fig. 3 Risk factors for diabetic peripheral neuropathy (continues variables)
Risk factors for diabetic peripheral neuropathy (binary variables)

Risk factor

Odds ratio and $95 \% \mathrm{Cl}$

$\begin{array}{lcr} & \begin{array}{c}\text { Odds } \\ \text { ratio }\end{array} & p \text {-value } \\ & & \\ \text { Ace inhibitor use } & 1.31 & 0.60 \\ \text { Alcohol use } & 1.04 & 0.82 \\ \text { Cardiovascular disease } & 2.22 & <.01 \\ \text { Excess alcohol use } & 1.11 & 0.47 \\ \text { Female } & 0.92 & 0.65 \\ \text { Foot ulcer history } & 1.90 & 0.02 \\ \text { History of smoking } & 1.31 & 0.07 \\ \text { Hypertension } & 1.90 & <.01 \\ \text { Insulin use } & 1.14 & 0.13 \\ \text { Macroalbuminuria } & 2.96 & <.01 \\ \text { Male } & 1.16 & 0.18 \\ \text { Micro- or macroalbuminuria } & 1.73 & <.01 \\ \text { Proliferative retinopathy } & 2.48 & <.01 \\ \text { Retinopathy } & 2.19 & <.01 \\ \text { Smoking } & 1.13 & 0.40 \\ \text { Statin use } & 0.79 & 0.44 \\ \text { White race } & 1.14 & 0.71\end{array}$

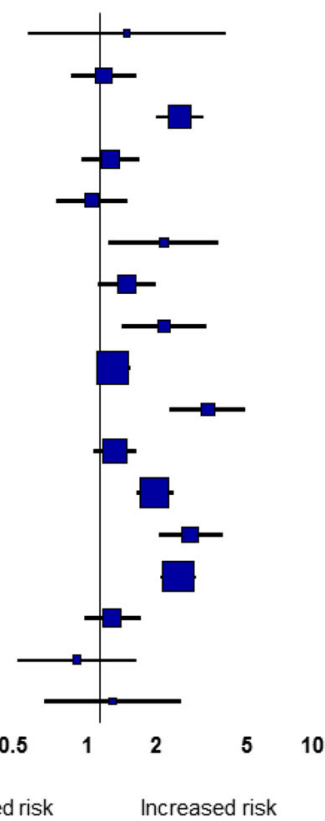

Risk factors for diabetic peripheral neuropathy (continuous variables)

Risk factor

$\begin{array}{lcc} & \text { Hedges's } & \\ & \boldsymbol{g} & \boldsymbol{p} \text {-value } \\ \text { Age } & 0.36 & <.01 \\ \text { Albumin/creatinine ratio } & 0.29 & 0.20 \\ \text { BMI } & 0.31 & <.01 \\ \text { Cholesterol } & 0.07 & 0.59 \\ \text { Cigarettes per day } & 0.40 & 0.38 \\ \text { Diabetes duration } & 0.47 & <.01 \\ \text { Diastolic blood pressure } & 0.19 & 0.21 \\ \text { eGFR } & 0.45 & <.01 \\ \text { Fibrinogen } & 0.10 & 0.03 \\ \text { HbA1c } & 0.24 & <.01 \\ \text { HDL } & 0.14 & <.01 \\ \text { Height } & 0.12 & 0.18 \\ \text { Insulin dose } & 0.05 & 0.28 \\ \text { LDL } & 0.15 & 0.24 \\ \text { Systolic blood pressure } & 0.31 & <.01 \\ \text { Triglycerides } & 1.16 & 0.10 \\ \text { Waist circumference } & 0.39 & <.01 \\ \text { Waist-hip ratio } & 0.10 & 0.30 \\ \text { Weight } & 0.34 & <.01\end{array}$

Hedges's g and $95 \% \mathrm{Cl}$

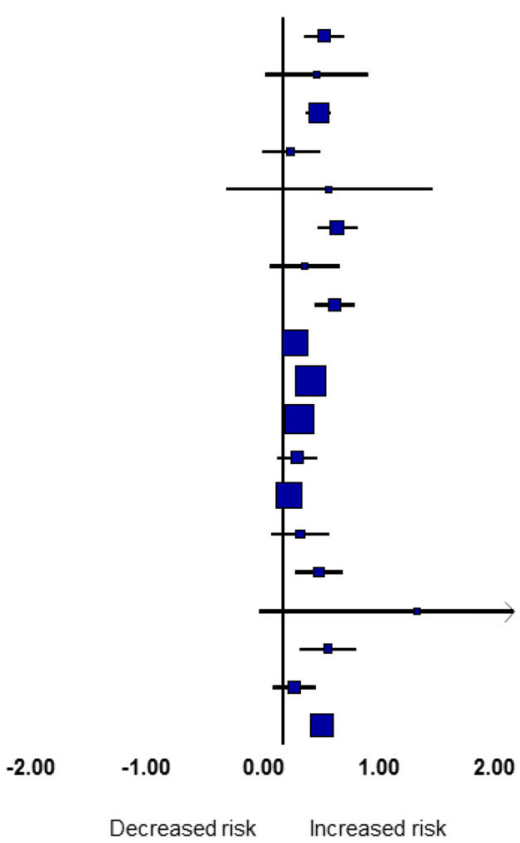


HbAlc values but also to focus on normal weight and awareness of the cardiovascular risk factors.

\section{Comparison with Other Studies}

Our findings are in line with previous studies which focused mostly on a limited number of risk factors for developing DPN.

A review published by Papanas and colleagues showed that risk factors duration of diabetes, age, hypertension and obesity are associated with developing DPN [35]. Papanas and colleagues observed a positive association between height and smoking and developing DPN. We did not observe any significant associations between these risk factors and developing DPN. Indeed, we included only prospective cohort studies and more recent studies that presented controversial results.

In our meta-analysis, smoking was investigated thoroughly. We investigated the association between the development of DPN and current smoking, past smoking and number of cigarettes smoked per day. Only past smoking was found to be a significant risk factor for DPN in our current study. One study found a positive association between current smoking and developing DPN [30]. Another study found a controversial effect of smoking on developing DPN [12]. All other studies in our current analyses for smoking did not show any significant effects of smoking on developing DPN $[2,4,7,10,16,33$, ]. A meta-analysis of 38 studies (10 prospective cohorts and 28 cross-sectional) by Clair and colleagues found a mild association between smoking and DPN (prevalent and incident DPN combined) [36]. However, in an analysis restricted to 10 prospective cohort studies, unadjusted for $\mathrm{HbAlc}$ and diabetes duration, no significant association was found between smoking and developing DPN [36]. Considerably, when 5 prospective studies were adjusted for HbAlc and diabetes duration, a positive association was found between smoking and developing DPN in the meta-analysis of Clair and colleagues. They also noted that studies including only participants with type 1 diabetes showed increased risks for developing DPN for smokers compared with non-smokers [36]. However, no distinction was made between current and past smokers. Numerous studies have demonstrated that smoking causes vasoconstriction and, indeed, vasoconstriction increases the risk of developing DPN $[37,38]$. The discrepancy in the results for smoking as a risk factor for developing DPN merits further investigation. More prospective cohort studies that make a distinction between current smoking, past smoking, smoking pack-years and diabetes type 1 and 2 are needed.

\section{Strengths and Limitations}

The major strength of our study is that we provide a comprehensive overview of meta-analytic evidence of risk factors for developing DPN. We have included prospective studies in which the participants had no DPN at baseline. We included prospective studies which were globally well distributed, had a sufficient follow-up period of at least 3 years and which were all of good quality according to our quality assessment.

Limitations are created by the degree of heterogeneity across studies which was mostly substantial, due to the variance in study populations used by included studies. Less common determinants, such as retinal thickness and corneal nerve fibre length, could not be investigated properly due to the lack of prospective studies available in the literature which investigated these determinants. Future prospective cohort studies should enlarge their scope regarding possible risk factors for developing DPN in a population with people with diabetes, including a follow-up period of at least 3 years and stratify their results in diabetes type and gender.

\section{Conclusions}

Our meta-analysis of prospective studies showed that age, BMI, duration of diabetes, eGFR, fibrinogen, $\mathrm{HbAlc}, \mathrm{HDL}$, systolic blood pressure, waist circumference, weight, cardiovascular disease, foot ulcer history, hypertension, macroalbuminuria, micro- or macroalbuminuria, proliferative retinopathy and retinopathy are risk factors which significantly contribute to the development of DPN. Modifiable risk factors such as high BMI and increased waist circumference can be changed by lifestyle modification and awareness.

Acknowledgements The authors thank L. Volkers for his help in designing the search strategy and data identification at the start of the current study and A.T. Wilson is thanked for critically reading the manuscript.

Authors' Contributions T.M. Fakkel, N. Çakici, J.W. van Neck, J.H. Coert and A. P. Verhagen designed the research. W. Bramer designed the search strategy and identified the study data. T.M. Fakkel and N. Cakici selected the studies and extracted study-level data. N. Cakici analysed and visualized the data. T.M. Fakkel, N. Çakici and J.W. van Neck drafted the article. J.W. van Neck, N. Çakici, T.M. Fakkel, J.H. Coert, A.P. Verhagen and W. Bramer made critical revisions related to the important intellectual content of the manuscript. N. Çakici and T.M. Fakkel wrote the article. Prior Presentation. This study was not presented prior to publication.

\section{Compliance with Ethical Standards}

Conflict of Interest The authors declare that they have no conflict of interest.

Open Access This article is licensed under a Creative Commons Attribution 4.0 International License, which permits use, sharing, adaptation, distribution and reproduction in any medium or format, as long as you give appropriate credit to the original author(s) and the source, provide a link to the Creative Commons licence, and indicate if changes were made. The images or other third party material in this article are included in the article's Creative Commons licence, unless indicated otherwise in a credit line to the material. If material is not included in the article's Creative Commons licence and your intended use is not permitted by statutory regulation or exceeds the permitted use, you will 
need to obtain permission directly from the copyright holder. To view a copy of this licence, visit http://creativecommons.org/licenses/by/4.0/.

\section{References}

1. Cakici N, Fakkel TM, van Neck JW, Verhagen AP, Coert JH. Systematic review of treatments for diabetic peripheral neuropathy. Diabet Med. 2016;33(11):1466-76.

2. Christen WG, Manson JE, Bubes V, Glynn RJ. Risk factors for progression of distal symmetric polyneuropathy in type 1 diabetes mellitus. Sorbinil Retinopathy Trial Research Group. Am J Epidemiol. 1999;150(11):1142-51.

3. Rigalleau V, Ybarra-Munoz J, Jurado-Campos J, Garcia-Gil M, Zabaleta-Del-Olmo E, Mir-Coll T, et al. Cardiovascular disease predicts diabetic peripheral polyneuropathy in subjects with type 2 diabetes: a 10-year prospective study. Diabetes Metab Res Rev. 2016;15(4):248-54.

4. Herder C, Kannenberg JM, Huth C, Carstensen-Kirberg M, Rathmann W, Koenig W, et al. Myeloperoxidase, superoxide dismutase-3, cardiometabolic risk factors, and distal sensorimotor polyneuropathy: the KORA F4/FF4 study. Diabetes-Metabolism Research and Reviews. 2018;34(5).

5. Al-Taweel Y, Fahmi R, Shehta N, Elserafy T, Allam H, Elsaid A. Frequency and determinants of subclinical neuropathy in type 1 diabetes mellitus. The Egyptian Journal of Neurology, Psychiatry and Neurosurgery. 2016;53(4):232-7.

6. mellitus. WHOFsND, https://www.who.int/mediacentre/factsheets/ fs 138/en/.

7. Yang CP, Lin CC, Li CI, Liu CS, Lin WY, Hwang KL, et al. Cardiovascular risk factors increase the risks of diabetic peripheral neuropathy in patients with type 2 diabetes mellitus: the Taiwan Diabetes Study. Medicine (Baltimore). 2015;94(42):e1783.

8. Cardoso CR, Salles GF. Predictors of development and progression of microvascular complications in a cohort of Brazilian type 2 diabetic patients. J Diabetes Complicat. 2008;22(3):164-70.

9. Tesfaye S, Chaturvedi N, Eaton SE, Ward JD, Manes C, IonescuTirgoviste $\mathrm{C}$, et al. Vascular risk factors and diabetic neuropathy. $\mathrm{N}$ Engl J Med. 2005;352(4):341-50.

10. Sibal L, Law HN, Gebbie J, Home P. Cardiovascular risk factors predicting the development of distal symmetrical polyneuropathy in people with type 1 diabetes: a 9-year follow-up study. Ann N Y Acad Sci. 2006;1084:304-18.

11. Lee CC, Perkins BA, Kayaniyil S, Harris SB, Retnakaran R, Gerstein $\mathrm{HC}$, et al. Peripheral neuropathy and nerve dysfunction in individuals at high risk for type 2 diabetes: the PROMISE Cohort. Diabetes Care. 2015;38(5):793-800.

12. Adler AI, Boyko EJ, Ahroni JH, Stensel V, Forsberg RC, Smith DG. Risk factors for diabetic peripheral sensory neuropathy. Results of the Seattle Prospective Diabetic Foot Study. Diabetes Care. 1997;20(7):1162-7.

13. Srinivasan S, Dehghani C, Pritchard N, Edwards K, Russell AW, Malik RA, et al. Optical coherence tomography predicts 4-year incident diabetic neuropathy. Ophthalmic Physiol Opt. 2017;37(4):451-9.

14. Elliott J, Tesfaye S, Chaturvedi N, Gandhi RA, Stevens LK, Emery $\mathrm{C}$, et al. Large-fiber dysfunction in diabetic peripheral neuropathy is predicted by cardiovascular risk factors. Diabetes Care. 2009;32(10):1896-900.

15. Dyck PJ, Davies JL, Wilson DM, Service FJ, Melton LJ 3rd, O’Brien PC. Risk factors for severity of diabetic polyneuropathy: intensive longitudinal assessment of the Rochester Diabetic Neuropathy Study cohort. Diabetes Care. 1999;22(9):1479-86.
16. Andersen ST, Witte DR, Dalsgaard EM, Andersen H, Nawroth P, Fleming T, et al. Risk factors for incident diabetic polyneuropathy in a cohort with screen-detected type 2 diabetes followed for 13 years: ADDITION-Denmark. 2018;41(5):1068-75.

17. Koivisto VA, Stevens LK, Mattock M, Ebeling P, Muggeo M, Stephenson J, et al. Cardiovascular disease and its risk factors in IDDM in Europe. EURODIAB IDDM Complications Study Group. Diabetes Care. 1996;19(7):689-97.

18. Tseng LN, Tseng YH, Jiang YD, Chang CH, Chung CH, Lin BJ, et al. Prevalence of hypertension and dyslipidemia and their associations with micro- and macrovascular diseases in patients with diabetes in Taiwan: an analysis of nationwide data for 2000-2009. J Formos Med Assoc. 2012;111(11):625-36.

19. Scholten, RJPM, Offringa, M, Assendelft, WJJ (red.). Inleiding in Evidence-Based Medicine. Klinisch handelen gebaseerd op bewijsmateriaal. Vierde herziene druk. Houten: Bohn, Stafleu, Van Loghum, 2013.

20. Moher D, Liberati A, Tetzlaff J, Altman DG. Preferred reporting items for systematic reviews and meta-analyses: the PRISMA statement. J Clin Epidemiol. 2009;62(10):1006-12.

21. Hedges LV. Distribution theory for Glass's estimator of effect size and related estimators. J Educ Stat. 1981;6(2):107-28.

22. Cohen J. Statistical power analysis for the behavioral sciences. L. Erlbaum Associates: Hillsdale; 1988.

23. DerSimonian R, Laird N. Meta-analysis in clinical trials. Control Clin Trials. 1986;7(3):177-88.

24. Bowden J, Tierney JF, Copas AJ, Burdett S. Quantifying, displaying and accounting for heterogeneity in the meta-analysis of RCTs using standard and generalised Q statistics. BMC Med Res Methodol. 2011;11:41.

25. Higgins JP, Thompson SG, Deeks JJ, Altman DG. Measuring inconsistency in meta-analyses. Bmj. 2003;327(7414):557-60.

26. Egger M, Davey Smith G, Schneider M, Minder C. Bias in metaanalysis detected by a simple, graphical test. Bmj. 1997;315(7109): 629-34.

27. Higgins JPT, Altman DG, Gøtzsche PC, Jüni P, Moher D, Oxman $\mathrm{AD}$, et al. The Cochrane Collaboration's tool for assessing risk of bias in randomised trials. BMJ (Clinical research ed ). 2011;343:d5928-d.

28. R Development Core Team (2008). R: a language and environment for statistical computing. R Foundation for Statistical Computing VhwR-po.

29. El-Salem K, Ammari F, Khader Y, Dhaimat O. Elevated glycosylated hemoglobin is associated with subclinical neuropathy in neurologically asymptomatic diabetic patients: a prospective study. J Clin Neurophysiol. 2009;26(1):50-3.

30. Forrest KY, Maser RE, Pambianco G, Becker DJ, Orchard TJ. Hypertension as a risk factor for diabetic neuropathy: a prospective study. Diabetes. 1997;46(4):665-70.

31. Rajaobelina K, Farges B, Nov S, Maury E, Cephise-Velayoudom FL, Gin H, et al. Skin autofluorescence and peripheral neuropathy four years later in type 1 diabetes. 2017;33(2).

32. Perkins BA, Orszag A, Ngo M, Ng E, New P, Bril V. Prediction of incident diabetic neuropathy using the monofilament examination: a 4-year prospective study. Diabetes Care. 2010;33(7):1549-54.

33. Coppini DV, Wellmer A, Weng C, Young PJ, Anand P, Sonksen $\mathrm{PH}$. The natural history of diabetic peripheral neuropathy determined by a 12 year prospective study using vibration perception thresholds. J Clin Neurosci. 2001;8(6):520-4.

34. Pritchard N, Edwards K, Russell AW, Perkins BA, Malik RA, Efron N. Corneal confocal microscopy predicts 4-year incident peripheral neuropathy in type 1 diabetes. Diabetes Care. 2015;38(4): 671-5.

35. Papanas N, Ziegler D. Risk factors and comorbidities in diabetic neuropathy: an update 2015. Rev Diabet Stud. 2015;12(1-2):4862 . 
36. Clair C, Cohen MJ, Eichler F, Selby KJ, Rigotti NA. The effect of cigarette smoking on diabetic peripheral neuropathy: a systematic review and meta-analysis. J Gen Intern Med. 2015;30(8):1193203.

37. Akishima S, Matsushita S, Sato F, Hyodo K, Imazuru T, Enomoto $\mathrm{Y}$, et al. Cigarette-smoke-induced vasoconstriction of peripheral arteries: evaluation by synchrotron radiation microangiography. Circ J. 2007;71(3):418-22.
38. Flynn MD, Tooke JE. Diabetic neuropathy and the microcirculation. Diabet Med. 1995;12(4):298-301.

Publisher's Note Springer Nature remains neutral with regard to jurisdictional claims in published maps and institutional affiliations. 